\title{
Thai Students' Understanding about Celestial Motion within Their Social and Cultural Context
}

\author{
Sakanan Anantasook, Khon Kaen University, Thailand \\ Chokchai Yuenyong, Khon Kaen University, Thailand \\ Anne Hume, University of Waikato, New Zealand
}

\begin{abstract}
This study investigated forty-one Thai $9^{\text {th }}$ grade students' understanding about the motion of the sun, moon, and stars within their social and cultural context. Students' understanding was explored using a survey tool titled "Students' Understanding about Celestial Motion within Their Social and Cultural Context Questionnaire (SCMSCQ)." This questionnaire gave students the opportunity to express their ideas about celestial motion within their social and cultural context. The study reveals some interesting features of student understanding, and particularly their difficulty in perceiving the relationship between the study of celestial motion and their social and cultural context. Many students used descriptions from their everyday observations of the daily motion of the sun, moon, and stars, rather than scientific explanations, to answer questions about the relationship between social and cultural context and celestial motion. This study has implications for the development of teaching the sociocultural approach in Thailand.
\end{abstract}

Keywords: Celestial Motion, Social and Cultural Context, Student Understanding

\section{Introduction}

$\mathrm{O}$ ne of the key areas of understanding for scientific literacy in the $21^{\text {st }}$ century involves astronomy (Plummer 2006) because it combines science and technology with inspiration and excitement. It can play a unique role in facilitating education and capacity-building for citizens in society and in furthering sustainable development throughout the world (Percy 1996). Percy $(1996,2005)$ also points out that knowledge of astronomy can increase public awareness, understanding, and appreciation of science and technology, which are important in all countries, both developed and developing. In the past, the excitement of astronomy has stimulated large numbers of teenagers to choose careers in science and technology, thereby contributing to the "knowledge economy" of many countries (International Astronomical Union [IAU] 2009).

Lebofsky, Canizo, and Lebofsky (1996) also state that astronomy can be used to introduce students to the natural world, which is a part of their lives. They emphasized it is highly relevant science because even children in an urban environment are aware of such phenomena as day and night, shadows, and the seasons. Astronomy is a science that transcends cultures, has been prominent in the news in recent years, and can generate excitement in young minds as no other science can. They also emphasize that astronomy is useful for understanding other science and mathematics concepts, and for developing problem solving skills, which are important in our technological world.

Consequently, teaching and learning astronomy in schools is highly justifiable. It not only prepare individuals for becoming astronomers in the future but also prepares citizens as a new generation who have deeper understanding of science, the ability to think critically and be able to explain astronomical phenomena that occur in everyday life and are relevant to their culture and society.

The learning of astronomy can be viewed as a process of cultural apprenticeship where members of society learn from their tutors or experts (Osborne 1996) and scientific knowledge is constructed as a form of "situated cognition" (Brown, Collins, and Duid 1989) that differs according to the boundary of thinking and the specific contexts (Coll, France, and Taylor 2005).

The International Journal of Science, Mathematics, and Technology Learning Volume 21, 2015, www.thelearner.com, ISSN 2327-7971

(C) Common Ground, Sakanan Anantasook, Chokchai Yuenyong, Anne Hume All Rights Reserved, Permissions: cg-support@commongroundpublishing.com 
This important view of knowledge grew from sociocultural theory (Dixon-Kraussm 1996) and a perspective of learning based on societal and cultural values (Yuenyong 2006). It suggests that situations within society influence the construction of astronomy knowledge and the teaching of astronomy concepts relevant to students' everyday should be carried out through sociocultural approaches to pedagogy.

Teaching and learning using a sociocultural approach typically encourages students to actively construct understanding by participation in cooperative learning activities and the negotiation of shared activities in social contexts (Teemant, Smith, Pinnegar, and Egan 2005). Such an approach also argues that: learners are active meaning-makers (Hatano 1993) through interaction and cooperation with one another (Driver, Asoko, Leach, Mortimer, and Scott 1994; Leach and Scott 2003; Shepardson 1999); the availability of multiple sources of information enhances knowledge construction (Hatano 1993); and adults, peers and communities play important roles in learning (Driver, Asoko, Leach, Mortimer, and Scott 1994; Kozulin 2003).

Since the sociocultural perspective provides ideas for teaching and learning based on society and cultural values it follows that learning of the astronomy should be related to social concerns or cultural perspectives to encourage meaningful science teaching and learning.

The main subject matter addressed in this study is celestial motion. Celestial motion is the term used for the motion of celestial objects such as the Sun, Moon, stars and planets (IAU 2009). Everyone can observe and visible the patterns of motion of the sun, moon and stars from the surface of the Earth. Key to understanding the nature of this motion is the concept that the Earth's rotation produces a continuous pattern of movement across the sky for all celestial objects. Thus, the Sun, Moon and stars all appear to slowly rise and set throughout the day and night while some stars appear to circle around the Earth's north or South Pole point in space. In addition, the Sun's position throughout the day and length of day are influenced by the Earth's tilted axis with respect to its orbit around the Sun, with the path of the Sun shifting higher in the summer and changing to lower angles in the winter. The Moon rises about 50 minutes later every consecutive night which slowly shows the moon phases as it orbits around the Earth (Institute for the Promotion of Teaching Science and Technology [IPST] 2008). A full scientific understanding of celestial motion concepts should includes both recognition of the observable patterns of change in the sun, moon and stars' locations as well as explanations for these astronomical phenomena (Plummer 2006).

Celestial motion concepts feature as key components of the astronomy and space performance indicators which are embedded in the 2008 Thai Science curriculum, particularly at the primary and lower secondary levels.

At the primary level, celestial motion concepts are concerned with those astronomical phenomena that can be found in daily life such as : the appearance of the Sun, Moon, and the stars in the sky (day and night); directions on the Earth; the movement of the stars; Moon phases; the seasons; and solar and lunar eclipses. Each concept is taught separately at each primary grade level and once students finish primary schooling there is a two year gap before they learn celestial motion concepts again at secondary school. At the lower secondary level, celestial motion concepts are concerned with the relationships between the Sun, the Earth, the Moon, constellations and other planets, and their effects on the environment and living things on Earth (IPST 2008).

Many studies have shown that students' understanding of celestial motion is challenging and difficult (Vosniadou and Brewer 1994; Sharp 1996; Adams and Slater 2000; Plummer 2006; Plummer, Wasko and Slagle 2011). These challenges include; firstly, children have limited experience of observing the change in location of the Sun, Moon and stars. Secondly, the apparent motion occurs so slowly that it is unperceivable by a single direct observation. Thirdly, it is difficult to accurately represent the appearance of objects in the three dimensional sky.

These are also the same research results in Thailand, for example; students faced difficulty learning and holding many misconceptions about Day and Night Cycle, and the Earth Moon Sun 
(EMS) system. Khongpugdee, Sukonthachat, and Phonphok (2009) reported that students held many misconceptions in (1) Scale; (2) Day and Night Cycle; (3) Season; (4) Moon phase; (5) Face of Moon; and (6) Eclipse. Factors believed to cause these difficulties include teachers' low capability in teaching astronomy and instructional models which did not support students' understanding. Dahsah, Phonphok, Pruekpramool, Sangpradit, and Sukonthachat (2012) also found that most of Thai secondary school students (grades 7-12) had no idea about sizes and distance of Earth-Moon-Sun (EMS) models. The students both underestimated and overestimated the distances, and overestimated the sizes. Banyong (2013) discussed that the students' prior mental representation of the celestial sphere and planetary motions could not be related their knowledge to daily phenomena. To address these issues, Khongpugdee (2010) designed the Earth Moon Sun (EMS) innovation for grade 9 students and in his study examined the effectiveness of inquiry methods using the EMS-Model on the learning of these concepts. The results showed improvement in students' basic astronomy concepts, science process skills, and scientific hobbits of mind. In another study, Banyong (2013) enhanced Grade 11 Thai students' mental representations about the positioning of stars on the celestial sphere and the planetary motions (e.g., celestial sphere and globe, angular distance, horizontal and equatorial coordinates, ecliptic coordinate, time, the Solar System model, planetary motions and elongation) through the PredictObserve-Explain (POE) strategy. It found that their mental representations were shown to converge more toward scientific explanation and they were able explain an everyday astronomical phenomena after the POE intervention.

In fact, celestial motion was the earliest concept in astronomical knowledge and a decisive factor in the emergence of agriculture and navigation in early civilizations (IAU 2009). It is not only deeply rooted in almost every culture (Percy 2005) but also still the basis of our modern system of time measurement such as the seasons and the calendar and of navigation and surveying (McNally 1982).

Thais also have developed their own knowledge on the apparent motion of the Sun, Moon and stars for a long time. It has influenced and appeared in many aspects of Thai society such as religious, cultural and intellectual beliefs. For example, Thais use the universal calendar, a form of solar calendar, in their daily activities, but use a lunar calendar in Muslim societies and in Buddhist societies. It used to determine important events which became linked to religion activities e.g, Full Moon days such as the Magha Puja Day (in the $3^{\text {nd }}$ month of the year), Vesaka Puja Day (in the $6^{\text {th }}$ month of the year), and Asalha Puja Day (in the $8^{\text {th }}$ month of the year) in Buddhist societies (Boonyotayan 2013). In addition, they knew well the cycles of the Sun and even which could determine the Equinox day (Boonyotayan 2006) (the day when the Sun rises in true east and set in true west) and the main sanctuary structures were placed relative to the rising and setting of the Sun (Anantasook 2011). These astronomical ideas influenced architectural design in important places such as the palace, towns, pagodas, chapel and residence from the past until now (Patwong 2012).

Thai knowledge about observing the stars was located in the "Tumradao". Many of Tumradao tell about how to read the stars, clouds, the sky, eclipses, comets, the moon and other astronomical phenomena for understanding predicting the effect of astronomical events on everyday lives. Thais also use the position, the rise and the setting of specific stars to tell of any auspicious times, the fate of towns and individuals (Pengkaew 2000). Thai lifestyle was also determined by the stars. People believed that the position of stars on the sky could be able to influence their life. Thai people believed these astrological objects are stars and the color of the day. Therefore, they dress and put on accessories according to their personal color specifying the day they were born on (Pluluang 1996).

The sun pathway was also studied for long in Thailand history. The dynasty of King Mongkut measured the height of the Sun from Earth and set a Siam clock tower in his palace at 100 degrees East longitude in order to establish Bangkok Mean Time in 1852. This achievement was earlier than Greenwich Mean Time which was set in 1880 . He appointed two positions 
officers for precise time keeping of the Siam clock - the first science work in Thailand. The first position was Pan Tiwathit (the sun officer) who observed and defined daytime from the Sun and the other was Pan Pinitchandra (the moon officer) who observed and defined nighttime from the Moon (Muanwong 1988).

In modern times, Thailand has seen a significant changes in astronomical research and education. Thai cabinet established the National Astronomical Research Institute of Thailand (NARIT), under the Ministry of Science and Technology in 2004. The institute aims are not only to establish the national facility (Soonthornthum 2009) but also promotes education and a learning culture in astronomy for the public encouraging further involvement by citizens with science and technology (Kramer 2007). In addition, the astronomy and space content were stipulated as one of eight strands in the science learning area in both the 2001 Basic National Education Curriculum and later in the 2008 Basic National Education Core Curriculum which is taught at every grade level. It is necessary for schools sciences to teach astronomy content as well as build and develop their students' thinking processes if students are to understand the causes and effects of astronomical phenomena in their daily lives (Klongsara and Charlee 2013), and with evidence from student's naked eyes and related to sociocultural activities (Boonyotayan 2013) where the values, norms, and beliefs of the larger society are played out (Yuenyong, Jones, and Yutakom 2008).

This study gives empirical data of student's perspective on astronomy teaching that may have implications for the development and evaluation of teaching using a sociocultural approach in the celestial motion unit for Thai students.

\section{Methodology}

\section{Participants}

The sample for the study consisted of 41 Grade 9 students, including 23 girls and 18 boys, from a school in the Surin province of Northeast Thailand. The majority of students' parents worked as farmers while a few were employed as labourers in the capital city of Thailand; Bangkok.

\section{Method}

Purpose-designed instruments i.e., questionnaires were used for explore students' understanding about celestial motion within their social and cultural contexts, in order to provide information for meaningful celestial motion teaching. Students were asked about the relationship between celestial motion, society and culture, taking into consideration these three dimensions, students' understanding about: (1) the influences of celestial motion on society and culture; (2) the influences of society and culture on celestial motion; and (3) how celestial motion knowledge influences the students' values and attitudes of daily life.

\section{The Development of the Research Instrument}

The Students' understanding about Celestial Motion within Social and Cultural context Questionnaire (SCMSCQ) consists of 10 multiple-choice items. The SCMSCQ was developed by setting the purpose, constructing the questions, carrying out an expert panel check of the content validity, and piloting. This method of constructing instruments was based on the Views on Science-Technology-Society (VOSTS) survey developed by Aikenhead and Ryan (1992). They developed the VOSTS using five steps. The steps are: 1. The content of the VOSTS statements was defined, and students' writing to give their opinion about these statements. 2. The multiplechoice questions are developed from students' free responses to the VOSTS statements. 3. The students are interviewed to edit the wording of the multiple-choice questions and ensure the student positions represent their viewpoints. 4. The multiple-choice VOSTS are evaluated by 
checking and revising them with a new group of students. 5. A large sample of students is surveyed and the results revised to form the final VOSTS questionnaire.

The SCMSCQ was checked by two science teachers and two science educators. The expert gave suggestions to ensure that all questions asked were aligned accurately with the purpose of the questionnaire but some questions needed to be edited. Therefore the questionnaire was piloted twice with Grade 10 students who completed their learning of celestial motion in the 2012 academic year, in two different schools on December 2013. The first pilot was used mainly to check student understanding of the questions. The second pilot was used to check both student understanding of the questions and the time students took to complete the questionnaire.

\section{Data Collection and Analysis}

Students completed the SCMSCQ, and the scores for students' understanding about celestial motion within their social and cultural context were presented as percentages for students' responses in each multiple choice that included no idea, agree, disagree, and their opinion. Then, the students' position understanding were compared and contrasted.

\section{Findings and Discussion}

\section{Students' Understanding about the Influences of Celestial Motion on Society and Culture}

This section discusses students' understanding about scientific knowledge (celestial motion) in influencing systems and their willingness to apply scientific knowledge and other forms of knowledge (e.g., philosophical, sociological, cultural, political, economic aspects and so on). The SCMSCQ (question 1-3 in Table 1) raised issues about the application of celestial motion knowledge related to societal and cultural aspects of students' lives.

When students had to consider the application of the rising and setting of the Sun on equinox day when constructing the chapel and sanctuary as described in question 1 in Table 1 , the majority of students $(59 \%)$ agreed with the idea of aligning the main construction with sunrise and sunset. This alignment lets the light go through the important thing in the centre of these buildings and allows it to be used as a solar calendar to hold activities related to their beliefs on important dates such as the day of the Vernal Equinox, Autumnal Equinox, Summer Solstice and Winter Solstice. In contrast, other students (29\%) focused on different reasons. They also agreed that the direction of the construction lying from East-West followed the main direction of Sun's movement but didn't consider the position of sunrise and sunset on Equinox day. It is considered to suitability area, identity design and benefits place. However, some students (12\%) didn't know enough about this subject to make a choice. It seemed that many students knew about the changing of the Sun's position in each season and its influence on the main core structure of religion buildings. The building was usually aligned with the direction of the Sun's movement.

Students were asked to give their opinions (agree or disagree) about the decision on whether or not to design houses related to the position of sunrises and sunsets for the purpose of saving energy (question 2 in Table 1). The majority of students (63\%) agreed with a decision to design house or buildings for saving energy. They thought that consideration should be given to sunlight through the house in each season, and other areas such as near the sea consideration should be given to the weather and wind direction when building. However, some students (27\%) disagreed with these ideas, their reasons being not concerns for saving energy from the Sun movement but focused on physical aspects. Their reasons including having the house facing the main road for a good view and the suitability of the area, identity design and benefits place. Interestingly, few students $(10 \%)$ gave different reasons from their view that the houses' style depend on their financial and situation or personal preferences. It seemed that more than half the students understood the Suns' pathway in each season and the benefits for saving energy in the building. 
Therefore, nowadays we can see the design of modern buildings usually relates to the direction of the Sun's movement.

When students were asked that the lunar timers is unimportant nowadays because the Universal calendar use effective worldwide (question 3 in Table 1), many students (49\%) disagreed about this question. Students thought that Universal calendar use well now but the lunar timers from the moon phase can created Lunar calendar that is another comfortable calendar which still use in Muslim and Buddhist societies. In contrast, other students (39\%) agreed that because electronic equipments can now tell the date and time easier. They also gave reason that the universal calendar specifies a Moon phases and important religious days for Muslim and Buddhist, so there's no need to use the lunar timers. However, some students (12\%) don't know enough about this issue. It seemed that students are difficult to understand about the lunar timers because the Universal calendar was use instead and its effective worldwide. Although many students know that lunar calendar use in both Muslim and Buddhist societies, they might not know how to create and use it.

Table 1: Students Responses to the Questions

\begin{tabular}{|c|c|c|c|c|c|c|c|c|}
\hline \multirow[t]{2}{*}{ Questions } & \multicolumn{2}{|c|}{ No Idea } & \multicolumn{2}{|c|}{ Agree } & \multicolumn{2}{|c|}{ Disagree } & \multicolumn{2}{|c|}{$\begin{array}{l}\text { Give } \\
\text { Opinion }\end{array}$} \\
\hline & $N$ & $\%$ & $N$ & $\%$ & $N$ & $\%$ & $N$ & $\%$ \\
\hline $\begin{array}{l}\text { 1. Construction of the chapel's and } \\
\text { sanctuary's main core has the foundation } \\
\text { related to position of the rise and set of the } \\
\text { Sun on equinox day. Do you agree or } \\
\text { disagree? Why? }\end{array}$ & 5 & 12.20 & 24 & 58.54 & 12 & 29.27 & 0 & 0.00 \\
\hline $\begin{array}{l}\text { 2. Building and house designs should be } \\
\text { related to the position of sunrises and } \\
\text { sunsets for saving energy. Do you agree or } \\
\text { disagree? Why? }\end{array}$ & 0 & 0.00 & 26 & 63.41 & 11 & 26.83 & 4 & 9.76 \\
\hline $\begin{array}{l}\text { 3. The lunar timers is unimportant } \\
\text { nowadays because the Universal calendar } \\
\text { is a solar calendar and use effective } \\
\text { worldwide. Do you agree or disagree? } \\
\text { Why? }\end{array}$ & 5 & 12.20 & 16 & 39.02 & 20 & 48.78 & 0 & 0.00 \\
\hline $\begin{array}{l}\text { 4. Should the government be encouraged to } \\
\text { give money to establish the big sundial in } \\
\text { community's park? Why? }\end{array}$ & 0 & 0.00 & 26 & 63.41 & 15 & 36.56 & 0 & 0.00 \\
\hline $\begin{array}{l}\text { 5. Should Thailand set a local's standard } \\
\text { time for each province? Why? }\end{array}$ & 0 & 0.00 & 2 & 4.88 & 39 & 95.12 & 0 & 0.00 \\
\hline $\begin{array}{l}\text { 6. Buddhist and Muslims use a lunar } \\
\text { calendar through observing the } \\
\text { appearance of the moon phases. The local } \\
\text { government should build a tower for } \\
\text { observing moon phases around their } \\
\text { temple or mosque. Do you agree or } \\
\text { disagree? Why? }\end{array}$ & 0 & 0.00 & 15 & 36.59 & 26 & 63.41 & 0 & 0.00 \\
\hline $\begin{array}{l}\text { 7. The celestial motion do not effect human } \\
\text { life because the Moon, Sun and stars are } \\
\text { the only objects in the universe. Do you } \\
\text { agree or disagree? Why? }\end{array}$ & 0 & 0.00 & 0 & 0.00 & 41 & 100 & 0 & 0.00 \\
\hline $\begin{array}{l}\text { 8. The coordinates of the position of } \\
\text { planets, constellations, and the zodiac }\end{array}$ & 0 & 0.00 & 10 & 24.39 & 31 & 75.61 & 0 & 0.00 \\
\hline
\end{tabular}




\begin{tabular}{|l|l|l|l|l|l|l|l|l|}
\hline $\begin{array}{l}\text { signs have no benefits for human daily } \\
\text { lives. Do you agree or disagree? Why? }\end{array}$ & & & & & & & & \\
\hline $\begin{array}{l}\text { 9. Investigating celestial objects using the } \\
\text { naked-eyed could create great imaginative } \\
\text { thought which is a starting point for a deep } \\
\text { interest in astronomy? Do you agree or } \\
\text { disagree? Why? }\end{array}$ & 0 & 0.00 & 38 & 92.68 & 3 & 7.32 & 0 & 0.00 \\
\hline $\begin{array}{l}\text { 10. Nowadays, Thais are more interested } \\
\text { in celestial motion i.e., the motion of the } \\
\text { Sun, Moon and stars. Do you agree or } \\
\text { disagree? Why? }\end{array}$ & 0 & 0.00 & 25 & 60.98 & 16 & 39.02 & 0 & 0.00 \\
\hline
\end{tabular}

Student responses for questions 1-3 showed the nature of their understanding in terms of the influence of scientific (celestial motion) knowledge on scientific applications and their social needs. Their ideas explicitly reflected that the direction of sun's movement was the main factor people considered when designing chapels, religion buildings, and modern houses. In addition, students firmly believed scientific knowledge (lunar timer), was still important for their societies but very difficult to understood. Therefore, many students need to create the lunar calendar from the real observation.

\section{Students' Understanding about the Influences of Society and Culture on Celestial Motion}

This section discusses students' understanding about systems, and volition of scientific application and other knowledge (e.g., philosophical, sociological, cultural, political, economic aspects and so on), with a focus on the learning of celestial motion. Students were asked about political issues including financial policy, setting the standard time and support learning place for religion community. Students selected choices, which represented their ideas.

The majority of students $(63 \%)$ thought that their respective governments should give money establish the big sundial in community's park (question 4 in Table 1). Their reasons focused on it would be a point of interest for tourism and it could be a astronomic learning-center for students. In contrast, others students (37\%) thought that is unnecessary it would be a waste of money. The governments should be spent that much money on other better projects. In addition, half of students in this group believe everyone has their own portable watch, so no there is no need for a sundial. It seemed that nearly 2 of 3 students wished has a big sundial establish in their societies. If the sundial designing specific for their culture and religion activities, it would be attractive for tourism and learning of sun watch.

Students were asked about the relationship between Thai's standard time and a local's standard time for each province which can set a little bit different time related to the sun's position. Most of students (95\%) known that is the same time (question 5 in Table 1). Students disagreed that politics should set a local's standard time for each province because Thailand has a standard time which can be used throughout the country. They exactly knew the reason that Thailand isn't as wide as China and the USA to set different time-zones. Furthermore, they also know the problem from a different time-zones, it would make difficult to set a time for meetings. However, some students thought that a standard time in Thailand should establish in the center of country (around 100 degrees East longitude) because Thai's standard time now set around 105 degrees East longitude. Another reason from students who agreed with the different idea (5\%) is they needed to known a local standard time in each province which related to the sun's position. It seemed that students known well about Thai's time-zones, however some idea shown that the time on each earth's position which related to the suns' position such as a solar noon time needed to teach them. 
The observing the appearance of the Moon phases was used to set the lunar calendar and determine the important religion days in Buddhist and Muslims societies. It is one of the issues that used to probe students' understanding about societal and cultural aspects influences on celestial motion. The majority of students $(63 \%)$ disagreed that the local government should build "a tower for observing moon phases" as technology for religion community at the temple or mosque (question 6 in Table 1). Their reasons focused on the valuable of observing moon tower, a modern observatory should be established instead or the budget should be spent on other better projects. Students also believe that Buddhists and Muslims could observe the moon using their naked eye anywhere, and nowadays they can check the Moon phases from the normal modern calendar. However, others students group (37\%) support the different ideas because they mainly believe the observing moon tower like a technology which can encourage more people to learn about astronomy. Their reasons did not take into account cultural aspects. A few students in this group chose reasons relating to the religion and culture. It seemed that most students might think that the place for observe the sky is important for their societies, but a modern observatory is more advantage than the place for specific observe the Moon. Interestingly, their reasons believe that naked eye can use effective for observe celestial motion, for example, the motion of the Moon.

The above findings indicated that students had easily understood the relationship between political issue and celestial motion knowledge. Students know that the Thai time zone which the government set is related to the sun's position and appropriate for Thailand. However, the majority of students' expressed the idea that finances should used for establish the astronomy learning in their community. These students thought that the government should give funding for creating a big sundial and a modern observatory in their society. Nevertheless, these places should be used to advantage for tourism and learning astronomy rather than only focus on observing moon phase which concerned with their religion activities.

\section{Students' Values and Attitudes as Influence on Celestial Motion Knowledge}

The values, attitudes, norms, and beliefs of each person in society tend to influence negotiations and data interpretation through social interaction. The celestial motion knowledge in student context might indicate their understanding of the advantage of the scientific (celestial motion) and other knowledge which we are socialized according to values and attitude. Students' values and attitudes about the celestial motion knowledge on daily life will be discussed.

When students were asked that the celestial motion do not affect human life (question 7 in Table 1), all students disagreed about this question. They believe firmly the motion of the Sun and the Moon exactly effect human life. Student's understanding separated into two main reasons at the same percentages. The first reason is the motion of the Sun and the Moon are used to specify a calendar. Particularly, the Moon is used to specify an important religious day and the Moon phase specifies the time tidal for fisher people. The second reason is many people in society have some astrology traditional activities which related to their beliefs and religion when the astronomical phenomena occur. Moreover, few students believe that the Sun, Moon and stars affect people's lives so they should learn and act according to the movement of these celestial objects. It could be assumed that students were exactly believe celestial motion have influence on human life but more than half of them concerned about the reasons of their beliefs, not scientific explanations.

When students were asked about the position of planets, constellations, and the zodiac signs have no benefits for human daily lives (question 8 in Table 1), the majority of students $(76 \%)$ disagreed that. Students mainly thought that the celestial object position affect people who were born in that zodiac so they should learn and act according to the movement of its, then their life become well. However, some students in this group given scientific reason that the position of the stars, planets and constellations could specify the direction, time, month or season. Others 
students group (24\%) thought that the coordinates of celestial objects are benefits only for astronomical study but it unnecessary in daily lives. It seemed that nearly 1 of 4 students known the benefits of the coordinates of celestial objects in astronomy inquiry. Other students were exactly known the benefits of the stars position in daily lives but more than half of them concerned about the reasons of their beliefs, not scientific explanations.

Students were asked to give their opinion (agree or disagree) about using the naked-eyed is a starting point for investigating celestial motions which is a good way to create students have imagination for a deep interest in astronomy (question 9 in Table 1). Interestingly, the majority of students (93\%) agreed that observing by naked-eyed is easy to encourage student have imagination. It is used to stimulate and generate scientific knowledge which is an important part of scientific inquiry. However, few students (7\%) disagreed with using it for observe the sky. The celestial objects observation need to use modern equipments. It might be said that most students are interesting to use the naked-eyed for observing celestial phenomena. It seemed that they need to construct their own knowledge by themselves.

When students were asked about the interest in celestial motion of Thais (question 10 in Table 1). The majority of students (61\%) agreed that Thais are more interested in celestial motion. Their reasons focused on the celestial motion knowledge concerns Thai cultural, living style and human daily lives. In addition, there are more observatories established now and celestial motion contents were teaching in school. However, some students (39\%) thought that Thais are less interested in the motion of the Sun, the Moon and the stars because there is an unpopular news' topic and people consider their jobs rather interesting than astronomy. It seemed that the interest in celestial motion of Thais depended on Thai cultures and societies such as the style of living, environmental setting, and mass communication.

Across the four questions, findings revealed that students' value and attitudes on celestial motion knowledge were based on their religion belief and background knowledge which they studied at the primary level. They firmly believed that the position and the motion of celestial objects influence human daily life but they were not using scientific explanations. Moreover, they were interested to use their naked-eyed for observing celestial movement and thought that Thais nowadays are increasingly interested in celestial motion knowledge because it appeared in Thai society and is embedded in Thai science curriculum.

\section{Conclusion and Suggestions}

This research revealed that Thai students' understanding about celestial motion was linked to their societal and cultural contexts. For example, they thought that the chapel's and sanctuary's main core construction, and also the modern building designs was related to the position of sunrise and sunset, based on their beliefs and scientific reasons. Because the lunar calendar was used in Muslim and Buddhism societies, they wished the government to encourage a place for learning and teaching how to observe the celestial phenomena by their naked-eyes. In addition, they believed that the position of celestial objects and their motions could effect and have benefit for human daily lives. However, many students usually used descriptions from their everyday observations of the daily apparent motion of the Sun, Moon and stars, rather than scientific explanations to answer questions which referred to the relationship between social and cultural contexts and celestial motion.

These findings suggest that Thai societal and cultural contexts could influence students' constructions of knowledge. Students form celestial motion understandings from both background knowledge that they gained at the primary school, and with phenomena in everyday life while acting under a system of cultures and beliefs. Teaching approaches for celestial motion should connect to familiar contexts and everyday life, then, to promote better learning. Engagement of Muslim and Buddhist activities, which are based on lunar calendar, in learning experiences may motivate students to know how to create and use lunar calendar in learning 
about celestial motion. The sociocultural approach could link related science (celestial motion) concepts to societal concerns or cultural perspectives (Bybee 1985). This study has implications for the development of teaching using the sociocultural approach in Thailand.

\section{Acknowledgements}

This research was financially supported by The Institute for Promotion Science and Technology Teaching (IPST), Thailand. I would like to acknowledge students and teachers in Surin province, Thailand.

\section{REFERENCES}

Adams, J., and T. Slater. 2000. Astronomy in the National Science Education Standards. Journal of Geoscience Education, 48: 39-45.

Aikenhead, G. B., and A. G. Ryan. 1992. The development of a new instrument: 'Views on Science-Technology-Society' (VOSTS). Science Education, 76(5), 477-491.

Anantasook, Sakanan. 2011. The Poster for Archaeo-Astronomy and Geology of Prasats in SURIN Province: the Learning Material. Proceedings of International Conference on Educational Research (ICER) 2011 : September 9-10, 2011, (pp.445-455). Khon Kaen : Faculty of Education, KKU, Thailand.

Banyong, Suthisa. 2013. Grade 11 students' Mental Representation about the positioning on the celestial sphere and the planetary motion through Predict-Observe-Explain (POE) Approach. Master of Education Thesis in Science Education,Graduate School, Khon Kaen University. Boonyotayan, Sansonthi. 2006. A 1,000 years Solar Calendar. Nakornpathom : Naiyanaprapai.

Boonyotayan, Sansonthi. 2013. Eratosthenes : measuring the world with a ruler. Action Training Handout. Pathunthani : National Science Museum. (Mimeographed).

Brown, J.S., A. Colin, and P. Duid. 1989. Situated Cognition and the culture of Learning. Educational Researcher, 18(1): 32-42.

Bybee, Rodger W. 1985. The Sisyphean question in science education: What should the scientifically and technologically literate person know, value and do-as a citizen? In R.W. Bybee (Ed.), Science-technology-society 1985 NSTA yearbook (pp. 79-93). Washington, D.C., USA: National Teacher Association.

Coll, R. K., B. France, and I. Taylor. 2005. The role of models/and analogies in science education: implications from research. International Journal of Science Education, 27 (2): 183-198.

Dahsah, Chanyah, Nason Phonphok, Chaninan Pruekpramool, Theerapong Sangpradit, and Jaturong Sukonthachat. 2012. Students' Conception on Sizes and Distances of the Earth-Moon-Sun Models. European Journal of Social Sciences, 32 (4): 583-597.

Dixon-Krauss, Lisbeth. 1996. Vygotsky in the Classroom: Mediated Literacy Instruction and Assessment. New York, USA: Longman.

Driver, R., H. Asoko, J. Leach, E. Mortimer, and P. Scott. 1994. Constructing scientific knowledge in the classroom. Educational Researcher, 23 (7): 5-12.

Hatano, Giyoo. 1993. "Time to merge vygotskian and constructivist conception of knowledge acquisition." In E. A. Forman, N. Minick, and C. A. Stone. (eds.). Context for Learning: Sociocultural Dynamic in Children's Development. New York: Oxford University Press, 153-166.

Institute for the Promotion of Teaching Science and Technology [IPST]. 2008. The Basic Education Core Curriculum B.E. 2551 (A.D. 2008) Science. Bangkok: Kurusapha Ladpraw. 
Institute for the Promotion of Teaching Science and Technology [IPST]. 2011. Teacher's Handout: Fundamental Science 6. Bangkok : Kurusapha Ladpraw.

International Astronomical Union [IAU]. 2009. Astronomy for the Developing World Building from the IYA2009: Strategic Plan 2010-2020. [online], Available at http://iau.org/static/ education/strategicplan_091001.pdf. [Accessed: 23 December 2013].

Kramer, Busaba. 2007. Astronomy in Thailand. Astronomy for the developing World: IAU Special Session, 5, 123-128.

Kozulin, Alex. 2003. "Psychological tools and mediated learning." In A. Kozulin, B. Gindis, Vladimir. S. Ageyev and Suzanne M. Miller.(eds.). Vygotsky's Educational Theory in Cultural Context. Cambridge, Cambridge University Press, 15-38.

Khongpugdee, Suwit. 2010. Effect of teaching astronomy based on inquiry method Using Earth Moon Sun system model (EMS-Model) innovation. Dissertation, Ph.D (Science Education). Bangkok: Graduate School, Srinakharinwirot University.

Khongpugdee, Suwit, Jutharat Sukonthachat, and Nason Phonphok. 2009. A study of conceptual understanding in basic astronomy of grade 9 and 10 students in rural areas of Thailand. Thai Journal of Physics, 4: 124-126.

Klongsara, Duangsamorn and Thanapun Charlee. 2013. "A Success Story-Astronomy and Earth Science in Thailand National Science Curriculum". In S. Komonjinda, Y.Y. Kovalev, and D. Rffolo. (eds.). The $11^{\text {th }}$ Asian-Pacific Regional IAU Meeting 2011. Chiangmai: NARIT Conference Series, Vol. 1, 439-441.

Leach, J., and P. Scott. 2003. Individual and sociocultural views of learning in Science education. Science \& Education, 12:91-113.

Lebofsky, L. A., T. Canizo, and N. R. Lebofsky. 1996. "Project Artist and Project Access! Integrating astronomy and planetary sciences into the elementary and middle school curriculum.” In J. R. Percy. (ed.). Astronomy Education: Current Developments, Future Coordination. San Francisco: BookCrafters, Inc., 235-236.

McNally, Derek. 1982. Astronomy at school. Physics Education, 17(4). 157-160.

Muanwong Khao. 1988. Confirmation the King Rama 4 exactly calculated the 1968 eclipses in Thailand by himself. Special book for celebration 300 years of Thai Astronomy, 61-76.

Osborne, Jonathan F. 1996. Beyond Constructivism. Science Education. 80 (1): 53-82.

Patwong,Watunyu. 2012. Astronomy and Architecture. Retrived on April 242013 from http://www.narit.or.th/index.php/2012-11-15-06-31-44/250-2013-02-04-03-49-52.

Pengkaew, Nipatporn. 2000. Stars Watching. Bangkok : Siam.

Percy, John R. 1996. “Astronomy education: An international perspective.” In J. R. Percy. (ed.). Astronomy Education: Current Developments, Future Coordination. San Francisco: BookCrafters, Inc., 1-8.

Percy, John R. 2005. "Why astronomy is useful and should be included in the science curriculum." In J.M. Pasachoff, and J.R. Percy. (eds.) Teaching and Learning Astronomy: Effective Strategies for Educators Worldwide. New York: Cambridge University Press, 10-13.

Pluluang. 1996. Siam Morals. Bangkok : Muang Boran.

Plummer, Julia D. 2006. Students' Development of Astronomy Concepts Across Time. Doctoral Dissertation, Ph.D (Astronomy and Education). USA: The University of Michigan.

Plummer, Julia D., Kyle D. Wasko, and Cynthia Slagle. 2011. Children Learning to Explain Daily Celestial Motion: Understanding astronomy across moving frames of reference. International Journal of Science Education, iFirst Article: 1-30.

Saiphet, Nipol. 2012. Amazing Human Being and Stars. Bangkok : Chulalongkorn University.

Sharp, John G. 1996. Children's astronomical beliefs: a preliminary study of Year 6 children in south-west England. International Journal of Science Education, 18(6): 685-712. 
Shepardson, Daniel P. 1999. Learning science in a first grade science activity: A Vygotskian perspective. Science Education, 83(5): 621-638. Soonthornthum, Boonrucksar. 2009. The Establishment of the National Astronomical

Research Institute in Thailand. The first Thailand-Korea Joint Workshop on Stellar Astrophysics, 151-158.

Teemant, A., M. E. Smith, S. Pinnegar, and M. W. Egan. 2005. "Modeling sociocultural pedagogy in distance education." Teachers College Record, 107 (8): 1675-1698.

Vanichai, Yupa. 1988. "The past and present state of astronomy education in Thailand.” In J. M. Pasachoff, and J. R. Percy. (eds.). The Teaching of Astronomy: Proceeding of the 105th Colloquium of the International Astronomical Union, Williamstown, Massachusetts, 2630 July 1988. New York: Cambridge University Press, 400-402.

Vosniadou, Stella, and William F. Brewer. 1994. Mental Models of the day/night cycle. Cognitive Science, 18: 123-183.

Yuenyong, Chokchai. 2006. Teaching and Learning About Energy: Science, Technology and Society (STS) Approach. Ph.D (Science Education). Bangkok: Kasetsart University.

Yuenyong, Chokchai, Alister Jones, and Naruemon Yutakom. 2008. A comparison of Thailand and New Zealand students' ideas about energy related to technological and societal issues. International Journal of Science and Mathematics Education, 6: 293-311.

\section{ABOUT THE AUTHORS}

Sakanan Anantasook: PhD Science Education Student, Faculty of Education, Khon Kaen University, Surin, Thailand

Dr. Chokchai Yuenyong: Assistant Professor, Faculty of Education, Khon Kaen University, Surin, Thailand

Dr. Anne Hume: Mathematics, Science, and Technology Education, Faculty of Education, University of Waikato, Hamilton, New Zealand 